\title{
Differential Control of Cocaine Self-Administration by GABAergic and Glutamatergic CBI Cannabinoid Receptors
}

\author{
Elena Martín-García ${ }^{1,2,3}$, Lucie Bourgoin ${ }^{1,2}$, Adeline Cathala',2, Fernando Kasanetz ${ }^{1,2}$, Miguel Mondesir ${ }^{1,2}$, \\ Ana Gutiérrez-Rodriguez ${ }^{4,5}$, Leire Reguero ${ }^{4,5}$, Jean- François Fiancette ${ }^{1,2}$, Pedro Grandes ${ }^{4,5}$, \\ Umberto Spampinato ${ }^{1,2}$, Rafael Maldonado ${ }^{3}$, Pier Vincenzo Piazza ${ }^{1,2}$, Giovanni Marsicano ${ }^{2,6}$ and \\ Véronique Deroche-Gamonet*,1,2 \\ 'INSERM U862, Pathophysiology of Addiction, NeuroCentre Magendie, Bordeaux, France; '2University of Bordeaux, Bordeaux, France; \\ ${ }^{3}$ Departament de Ciencies Experimentals i de la Salut, Universitat Pompeu Fabra, PRBB, Barcelona, Spain; ${ }^{4}$ Department of Neurosciences, Faculty \\ of Medicine and Dentistry, University of the Basque Country UPVIEHU, Leioa, Spain; ${ }^{5}$ Achucarro Basque Center for Neuroscience, Bizkaia Science \\ and Technology Park, Zamudio, Spain; 'INSERM U862, Endocannabinoids and Neuroadaptation, NeuroCentre Magendie, Bordeaux, France
}

\begin{abstract}
The type I cannabinoid receptor ( $\mathrm{CBI}$ ) modulates numerous neurobehavioral processes and is therefore explored as a target for the treatment of several mental and neurological diseases. However, previous studies have investigated CBI by targeting it globally, regardless of its two main neuronal localizations on glutamatergic and GABAergic neurons. In the context of cocaine addiction this lack of selectivity is critical since glutamatergic and GABAergic neuronal transmission is involved in different aspects of the disease. To determine whether CBI exerts different control on cocaine seeking according to its two main neuronal localizations, we used mutant mice with deleted $C B \mathrm{I}$ in cortical glutamatergic neurons (Glu-CBI) or in forebrain GABAergic neurons (GABA-CBI). In Glu-CBI, gene deletion concerns the dorsal telencephalon, including neocortex, paleocortex, archicortex, hippocampal formation and the cortical portions of the amygdala. In GABA$\mathrm{CBI}$, it concerns several cortical and non-cortical areas including the dorsal striatum, nucleus accumbens, thalamic, and hypothalamic nuclei. We tested complementary components of cocaine self-administration, separating the influence of primary and conditioned effects. Mechanisms underlying each phenotype were explored using in vivo microdialysis and ex vivo electrophysiology. We show that CBI expression in forebrain GABAergic neurons controls mouse sensitivity to cocaine, while CBI expression in cortical glutamatergic neurons controls associative learning processes. In accordance, in the nucleus accumbens, GABA-CBI receptors control cocaine-induced dopamine release and Glu-CBI receptors control AMPAR/NMDAR ratio; a marker of synaptic plasticity. Our findings demonstrate a critical distinction of the altered balance of Glu-CBI and GABA-CBI activity that could participate in the vulnerability to cocaine abuse and addiction. Moreover, these novel insights advance our understanding of CBI neuropathophysiology.

Neuropsychopharmacology (20 I6) 4I, 2192-2205; doi:I0.1038/npp.20 I5.35 I; published online I3 January 20 I6
\end{abstract}

\section{INTRODUCTION}

As a reward-related behavior, cocaine taking involves interacting psychological components, including reinforcement, reward, motivation, response inhibition, and response to drug discriminative or conditioned cues (Berridge et al, 2009). Although the picture is still fragmented, these psychological components appear to rely on interconnected prefrontal-subcortical neuronal circuits that process motivational and discriminative value of the drug and drug-related stimuli (Goldstein and Volkow, 2011) vs cognitive inhibitory control (Kober et al, 2010; Mihindou et al, 2013; Volkow et al, 2010). In these circuits, notably within the nucleus

* Correspondence: Dr V Deroche-Gamonet, CRI U862, Pathophysiology of Addiction, Neurocentre Magendie, 146 rue Léo Saignat, Bordeaux 33077, France, Tel: +33 5575736 80, Fax: +33 5575736 69, E-mail: veronique.deroche@inserm.fr

Received 12 June 2015; revised 13 November 2015; accepted 19 November 2015; accepted article preview online 27 November 2015 accumbens (Kalivas, 2009; Wolf and Ferrario, 2010) (NAc), glutamate (Glu) and GABA have major roles in controlling cocaine self-administration by modulating mesolimbic dopamine (DA), the primary neurochemical substrate for cocaine's reinforcing/rewarding properties. Converging data point to a specific role of cortical Glu projections in controlling drug seeking through learning processes (Bowers et al, 2010; Briand et al, 2014; Pierce and Wolf, 2013; Schmidt and Pierce, 2010; Suto et al, 2013; Xi et al, 2006). Alternatively, subcortical forebrain GABA transmission is thought to be indirectly involved in the reinforcing properties of cocaine and cocaine-related stimuli (Roberts, 2005; Vlachou and Markou, 2010) by modulating the perception of drug-related rewards (Tachibana and Hikosaka, 2012).

The endocannabinoid system, mainly through type 1 cannabinoid receptors (CB1) located on glutamatergic (glutamatergic $\mathrm{CB} 1$ ) and GABAergic neurons (GABAergic CB1), control both excitatory and inhibitory neurotransmission, thereby modulating dopaminergic-dependent behaviors 
(Melis and Pistis, 2012; Dubreucq et al, 2013), including cocaine seeking (De Vries and Schoffelmeer, 2005). Full pharmacological antagonism of CB1 decreases the influence of conditioned factors on cocaine seeking and on extracellular Glu and DA in the NAc (Caillé and Parsons, 2006; Cheer et al, 2007; Oleson and Cheer, 2012; De Vries et al, 2001; Xi et al, 2006), as well as expression of cocaine-induced behavioral sensitization in a context-specific manner (Gerdeman et al, 2008). Differently, full pharmacological blockade or complete genetic deletion of CB1 does not affect, or only marginally affect (Chaperon et al, 1998; Soria et al, 2005), the primary reinforcing (Cossu et al, 2001; De Vries et al, 2001; Caillé and Parsons, 2006) and rewarding properties of cocaine (Houchi et al, 2005; Martin et al, 2000), as well as the underlying DA and GABA mechanisms (Caillé and Parsons, 2006; Soria et al, 2005; De Vries and Schoffelmeer, 2005). Together these data suggest that the primary role of the endocannabinoid system in cocaine selfadministration is to control conditioning-related processes that largely depend on glutamatergic transmission (De Vries and Schoffelmeer, 2005; Wiskerke et al, 2008).

However, full genetic deletion or pharmacological blockade of CB1 might produce a biased effect and obscure the combined functions of the glutamatergic and GABAergic CB1 pools. When targeted genetic deletion of CB1 is applied in feeding-, novelty-, and fear-related behaviors (Bellocchio et al, 2010; Dubreucq et al, 2012; Metna-Laurent et al, 2012), deletion localized to cortical glutamatergic neurons (GluCB1-KO mice) produces similar effects to full CB1 blockade, apparently confirming that CB1 exclusively controls glutamatergic-dependent processes (Bellocchio et al, 2010; Dubreucq et al, 2012; Metna-Laurent et al, 2012). However, deletion of CB1 in forebrain GABAergic neurons (GABA$\mathrm{CB} 1-\mathrm{KO}$ mice) is not without effect. Interestingly, it can produce opposing or qualitatively different results as compared with deletion in cortical glutamatergic neurons (Bellocchio et al, 2010; Dubreucq et al, 2012; Metna-Laurent et al, 2012).

Considering the specific contribution of excitatory or inhibitory neurotransmission in distinct components of cocaine self-administration, we explored the specific roles of $\mathrm{CB} 1$ located in glutamatergic and GABAergic neurons. We used the two mutant mouse lines targeting $\mathrm{CB} 1$ deletion in cortical glutamatergic (Glu-CB1-KO) and forebrain GABAergic (GABA-CB1-KO) neurons (Marsicano et $a l, 2003)$ to test complementary components of cocaine self-administration, involving primary and secondary reinforcing properties of cocaine. In the Glu-CB1-KO mice, the $\mathrm{CB} 1$ gene is primarily absent in cortical glutamatergic neurons in the dorsal telencephalon, including neurons located in neocortex, paleocortex, archicortex, hippocampal formation and the cortical portions of the amygdala. In the GABA-CB1-KO mice, the $C B 1$ gene is primarily absent in forebrain GABAergic neurons, that is, in several cortical and non-cortical regions, eg the striatum, NAc and some thalamic and hypothalamic nuclei (Marsicano and Lutz, 1999; Monory et al, 2006; Marsicano and Kuner, 2008; Bellocchio et al, 2010).

Considering the role of meso-accumbal DA in mediating cocaine primary reinforcing effects (Di Chiara et al, 2004), freely moving naïve rodents were tested for cocaine-induced extracellular DA in the NAc using in vivo microdialysis. Last, because cocaine produces sustained alterations in glutamatergic-dependent synaptic plasticity in the NAc (Guercio et al, 2015; Kalivas and Volkow, 2011; Ortinski et al, 2012; Pascoli et al, 2014; Ma et al, 2014) that are critical for associative learning (Pierce and Wolf, 2013; Schmidt and Pierce, 2010), we quantified AMPAR/NMDAR ratio as a maker of synaptic plasticity in the NAc of cocaineexperienced mice, using ex vivo electrophysiology.

\section{MATERIALS AND METHODS}

\section{Animals}

CB1-KO mice were generated by crossing mice bearing the floxed $C B 1$ gene with transgenic mice expressing Cre recombinase (Marsicano et al, 2002). To dissect the roles of $\mathrm{CB} 1$ receptors on cortical excitatory or forebrain inhibitory neurochemical transmission, we used conditional mutant mice (Bellocchio et al, 2010; Marsicano et al, 2002; Monory et al, 2007). Experimental animals were acquired from 'floxed' (CB1loxP/loxP) mothers mated with 'floxed' fathers that also specifically expressed Cre recombinase in either cortical glutamatergic neurons (Nex-cre) or forebrain GABAergic cells (Dlx5/6-cre). The progeny of these couples were, therefore, either 'floxed' with or without the Cre recombinase expression. Mice not expressing Cre recombinase are here defined as Glu-CB1-WT and GABA$C B 1-W T$ controls, whereas their mutant littermates are called Glu-CB1-KO (CB1loxP/loxP; Nex-cre mice) and GABA-CB1KO (CB1loxP/loxP; Dlx5/6-cre mice), respectively (Bellocchio et al, 2010; Monory et al, 2006, 2007; Soria-Gómez et al, 2014).

All mice were genotyped before experiments and re-genotyped afterwards, and all WT mice were confirmed to lack Cre expression.

Animal procedures were conducted in strict accordance with the guidelines of the European Communities Directive 86/609/EEC regulating animal research.

\section{CB1 Immunohistochemistry}

Immunohistochemical detection of $\mathrm{CB} 1$ receptors in the brain of WT, Glu-CB1-KO, GABA-CB1-KO, and full CB1-KO, was performed as previously described by Reguero et al (2011).

Briefly, coronal brain vibrosections $(50 \mu \mathrm{m})$ were collected. Immunohistochemistry for the detection of $\mathrm{CB} 1$ was performed on these brain slices by means of a pre-embedding immunoperoxidase method, and later visualized using light microscopy.

Brain deletion of the $C B 1$ gene in Glu-CB1-KO and GABA-CB1-KO has been demonstrated previously (Monory et al, 2006, 2007; Soria-Gómez et al, 2014; Bellocchio et al, 2010). Here we focused on brain structures relevant to the present study (Figure 1).

\section{Jugular Vein Catheterization}

Surgery was performed under ketamine $(80 \mathrm{mg} / \mathrm{kg}$, Imalgène, MERIAL, Lyon, France)/xylazine (16 mg/kg, Rompun, Bayer HealthCare, Puteaux, France) anesthesia as previously described (Fiancette et al, 2010; van der Veen et al, 2007). 


\section{Cocaine Intravenous Self-Administration}

Basal training. A $2 \mathrm{~h}$ cocaine self-administration session was conducted daily 7 days per week. Self-administration was established using a FR1-FR2, $20 \mathrm{~s}$ time out schedule of reinforcement. During the initial three sessions, one nose poke into the active manipulandum (active hole) resulted in one infusion of cocaine, ie an FR1 schedule. It was followed by an FR2 for the rest of the experiment. Completion of the FR illuminated the white cue light, located above the active hole, and then $1 \mathrm{~s}$ later, the infusion pump was switched for $2 \mathrm{~s}$. The white cue light remained on for a total of $4 \mathrm{~s}$. Nose
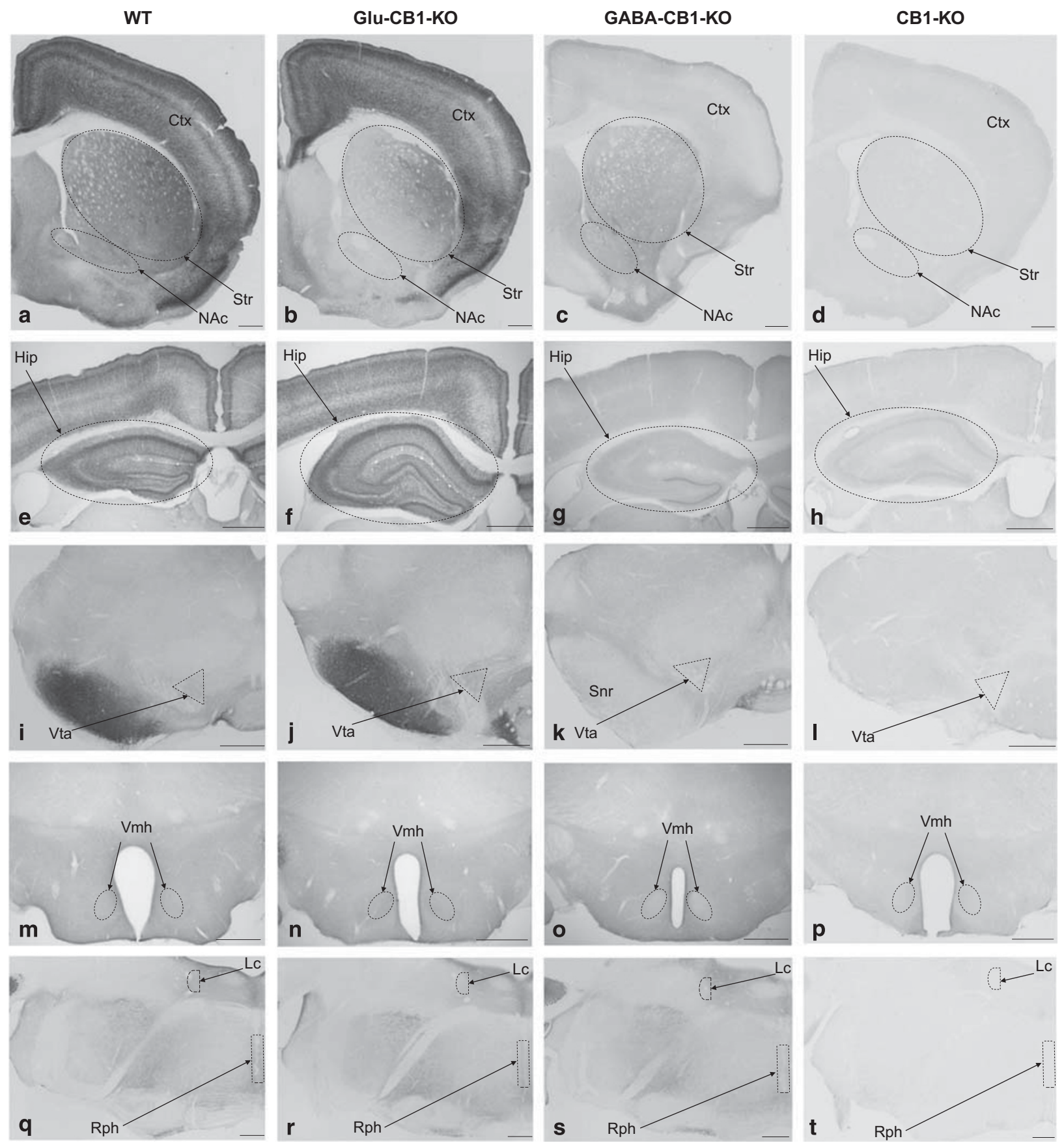

Figure I CBI protein brain expression in WT, Glu-CB I-KO, GABA-CB I-KO and CB I-KO mice. Cortex (in a-d), striatum (striped oval in a-d), nucleus accumbens (striped oval in a-d), hippocampus (striped oval in $\mathrm{e}-\mathrm{h}$ ), ventral tegmental area (striped triangle in $\mathrm{i}-\mathrm{l}$ ), substantia nigra pars reticulata (in $\mathrm{i}-\mathrm{l}$ ), ventromedial nucleus of the hypothalamus (striped oval in $\mathrm{m}-\mathrm{p}$ ), raphe nuclei (striped rectangle in $\mathrm{q}-\mathrm{t}$ ) and locus coeruleus (striped semi-circle in $\mathrm{q}-\mathrm{t}$ ). Only unspecific diaminobenzidine background is detected in $C B I-K O$ tissue. Relative to WT mice, the Glu-CBI-KO showed a mild decrease in CBI immunoreactivity while the GABA-CBI-KO showed a more pronounced decrease. $C B \mid$ labeling in dorsomedial and ventral striatum is reduced in Glu-CBI$K O(b)$, whereas substantia nigra pars reticulata lacks $C B I$ staining in GABA-CBI-KO $(k)$. Note the typical strong $C B \mid$ pattern in the inner $I / 3$ of the dentate molecular layer of GABA-CB I-KO (g). Ctx, Cortex; Hip, Hippocampus; Lc, locus coeruleus; NAc, nucleus accumbens; Rph, raphe nuclei; Snr, substantia nigra pars reticulata; Str, Striatum; Vmh, ventromedial nucleus of hypothalamus; Vta, ventral tegmental area. Scale bars: $500 \mu \mathrm{m}$. 
pokes in the inactive manipulandum (inactive hole) had no scheduled consequences. Criteria for acquisition of cocaine self-administration were defined as a stable number of self-infusions and significant discrimination between active and inactive holes, over at least three consecutive self-administration sessions $( \pm 20 \%)$.

Determination of the training dose. In a preliminary experiment, both lines of mice were trained at the same dose of cocaine of $0.5 \mathrm{mg} / \mathrm{kg} /$ infusion. At this dose, $64 \%$ of GluCB1-KO and $78 \%$ of Glu-CB1-WT mice acquired selfadministration. Similarly, $70 \%$ of the GABA-CB1-WT mice expressed self-administration, but only $37 \%$ of the GABACB1-KO mice reached criteria, with several showing clear signs of avoidance, suggesting increased sensitivity to cocaine in GABA-CB1-KO mice. Based on this observation, one independent group of GABA-CB1 mice was tested at the dose of $0.25 \mathrm{mg} / \mathrm{kg} /$ infusion, for which $60 \%$ of GABA-CB1$\mathrm{KO}$ and $70 \%$ of GABA-CB1-WT mice expressed selfadministration. Based on these preliminary experiments, the doses of $0.25 \mathrm{mg} / \mathrm{kg} /$ infusion and $0.5 \mathrm{mg} / \mathrm{kg} /$ infusion were selected for training in GABA-CB1 and Glu-CB1 mice, respectively. Differential drug history can greatly influence levels of responding for cocaine and compromise comparison of Glu-CB1 to GABA-CB1 mice, but our goal was to study the effect of $\mathrm{CB} 1$ deletion within specific subpopulations of neurons, which mandatorily required comparing the mutant lines to their respective WT.

Progressive-ratio reinforcement schedule. During this schedule, the number of responses per infusion was increased after each infusion $(1,3,5,7,9,15,20,25,33$, $43,55,70,80,90,100,110,121,132,144,158,175,195,219$, $247,279,315,355,399,447)$. The session ended after either $3 \mathrm{~h}$ or following $1 \mathrm{~h}$ since the last earned infusion.

Cue-induced cocaine seeking. This was performed over one session during which cocaine was not available. Following a 60 min period during which nose pokes were not reinforced (active and inactive nose pokes producing no scheduled consequences), the white cue light, associated with cocaine infusions during cocaine self-administration sessions, was illuminated contingently for $30 \mathrm{~min}$ (according to an FR2, comparable to the one used for cocaine selfadministration). To signal the change in the schedule, the cue light was presented twice non-contingently and during $4 \mathrm{~s}$.

Cue omission. This session was similar to a basal training session, except that the cue light associated with cocaine delivery was omitted.

Shock-induced suppression of cocaine taking. During this $45 \mathrm{~min}$ session, mice were placed in the self-administration chamber with the opaque PVC floor replaced by a metal grid that served to deliver electric foot shocks and constituted a discriminative stimulus. The schedule was the following: after one response in the active hole, mice received an electric shock ( $0.1 \mathrm{~mA}, 2 \mathrm{~s})$, and after the second response, mice received the combined stimuli of an electric shock, a cocaine infusion, and the cocaine cue light. The schedule reinitiated at the end of the $20 \mathrm{~s}$ time out period following the infusion. If within 1 min mice did not complete the response requirement leading to shock plus infusion, the sequence was reinitiated.

Shock-induced conditioned suppression of cocaine seeking. During this $45 \mathrm{~min}$ session, mice were placed in the selfadministration chamber containing the grid floor for delivering shock. During this session, nose pokes were without scheduled consequences, neither cocaine infusion, cue nor shock.

Reversal learning. This session was similar to the basal training sessions except that the active and the inactive holes were reversed.

\section{T-Maze}

In this test, mice were required to enter the reinforced arm of a maze to obtain food and to reverse this behavior once established. To this end, mice underwent habituation, acclimation, forced-choice, free choice, and reversal freechoice training. Latency to reach the goal arm and accuracy level were recorded.

\section{In vivo Microdialysis in the NAc for Extracellular DA in Freely Moving Mice}

Surgery and perfusion procedure were performed according to a previously described protocol (Panin et al, 2012), with minor modifications. Briefly, animals were anesthetized with a mixture of ketamine $(80 \mathrm{mg} / \mathrm{kg}$, i.p., Imalgène, Merial, France) and xylazine $(16 \mathrm{mg} / \mathrm{kg}$, i.p., Rompun, Bayer, France). Afterwards, animals were placed in a stereotaxic frame (David Kopf Instruments, Phymep, Paris, France), and their rectal temperature was monitored and maintained at $37 \pm 1^{\circ} \mathrm{C}$ by a heating pad (CMA 150, Carnégie Medecin, Phymep). After exposing the dorsal skull, one hole was drilled for implanting a microdialysis probe (CMA/7, Cuprophan, $240 \mu \mathrm{m}$ outer diameter, $1 \mathrm{~mm}$ length, Carnegie Medicin, Phymep) into the medio-ventral part of the right NAc. The stereotaxic coordinates (Franklin and Paxinos, 2012) (in $\mathrm{mm}$ relative to bregma) were as follows: anteroposterior $=+1.4$, lateral $=0.6$, and ventral $=-5$. The probe was secured with dental cement. Experiments were performed in freely moving mice, $24 \mathrm{~h}$ after surgery. In each experimental group, animals received either cocaine or its vehicle according to a randomized design. The probe was perfused at a constant rate $(1.1 \mu \mathrm{l} / \mathrm{min})$ by means of a microperfusion pump (CMA 111, Carnegie Medicin, Phymep) with artificial cerebrospinal fluid containing (in $\mathrm{mM}$ ): 154.1 $\mathrm{Cl}-, 147 \mathrm{Na}+, 2.7 \mathrm{~K}+, 1 \mathrm{Mg}^{2+}$, and $1.2 \mathrm{Ca}^{2+}$, adjusted to $\mathrm{pH} 7.4$ with $2 \mathrm{mM}$ sodium phosphate buffer.

\section{Ex vivo Electrophysiology in the NAc}

Slice preparation. Mice were deeply anesthetized with isoflurane and transcardially perfused with a sucrose-based physiological solution at $4{ }^{\circ} \mathrm{C}$ (in $\mathrm{mM}$ : $87 \mathrm{NaCl}, 75$ sucrose, 25 glucose, $5 \mathrm{KCl}, 21 \mathrm{MgCl}_{2}, 0.5 \mathrm{CaCl}_{2}$, and $\left.1.25 \mathrm{NaH}_{2} \mathrm{PO}_{4}\right)$. Brains were removed and sliced $(300 \mu \mathrm{m})$ in the coronal plane. Slices were then stored for $40 \mathrm{~min}$ at $32^{\circ} \mathrm{C}$ in an artificial cerebrospinal fluid (ACSF; in $\mathrm{mM}$ ): $130 \mathrm{NaCl}, 11$ glucose, $2.5 \mathrm{KCl}, 2.4 \mathrm{MgCl}_{2}, 1.2 \mathrm{CaCl}_{2}, 23 \mathrm{NaHCO}_{3}, 1.2$ 


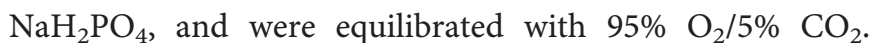
Afterwards, slices were stored in ACSF at room temperature until recording. Slices were then placed in the recording chamber and superfused (1.5-2 $\mathrm{ml} / \mathrm{min}$ ) with ACSF containing the $\mathrm{GABA}_{\mathrm{A}}$ receptor antagonist picrotoxin $(50 \mu \mathrm{M})$ (SIGMA, St Quentin Fallavier, France). All experiments were performed at $\sim 30^{\circ} \mathrm{C}$. All drugs were added at the final concentration to the superfusion medium.

Recording procedures. Whole cell patch clamp recordings were performed on visualized medium spiny neurons located in the shell part of the nucleus accumbens (NAcshell). Glass electrodes (resistance 4-6 M 2 ) were filled with: 125gluconic acid, $125 \mathrm{CsOH}, 10$ HEPES, $10 \mathrm{NaCl}, 0.3$ EGTA, 0.05 Spermine, 10 TEA-Cl, $2 \mathrm{MgCl}_{2}, 0.3 \mathrm{CaCl}_{2}, 4 \mathrm{Na}_{2} \mathrm{ATP}, 0.3$ NaGTP, 0.2 cAMP, pH 7.3, osmolarity 290-300 mOsm. Recordings were performed with an Axopatch-1D amplifier (Molecular Devices, Sunnyvale, CA). Data were filtered at $1-2 \mathrm{kHz}$, digitized at $10 \mathrm{kHz}$ on a Digidata $1332 \mathrm{~A}$ interface (Molecular Devices), collected on a PC using Clampex 9, and analyzed using Clampfit 10 (Molecular Devices). Throughout the experiments access resistance $(\mathrm{Ra})$ was evaluated with a $2 \mathrm{mV}$ hyperpolarizing pulse. Ra was not compensated and cells were rejected, if $\mathrm{Ra}$ was $>25 \mathrm{M} \Omega$ or changed $>20 \%$ during the experiment. The potential reference of the amplifier was adjusted to zero before breaking into the cell. To evoke synaptic currents, stimuli (100 ms duration) were delivered at $0.1 \mathrm{~Hz}$ with a glass electrode filled with ACSF and placed at a distance $>150 \mu \mathrm{m}$ from the recorded neuron.

AMPAR/NMDAR ratio. AMPAR-mediated EPSC were evoked while holding cells at $-70 \mathrm{mV}$. After $10 \mathrm{~min}$ of stable EPSC amplitude, cells were depolarized to $+40 \mathrm{mV}$ to unveil a dual component (AMPAR+NMDAR mediated) EPSC. The AMPAR/NMDAR ratio was calculated as the peak value of AMPAR-mediated EPSC recorded at $-70 \mathrm{mV}$ over the dual component EPSC amplitude measured $40 \mathrm{~ms}$ after its onset (a time point where AMPAR-mediated EPSC already decayed to zero).

\section{Experiment 1: Dose-Response Curves in Cocaine Intravenous Self-Administration in Glu-CB1 and GABA-CB1 Mice}

Four days after surgery, mice were trained for cocaine selfadministration. Daily sessions started $2 \mathrm{~h}$ after the beginning of the dark phase. Training doses were defined based on preliminary experiments (see above in 'cocaine intravenous self-administration'): 0.25 and $0.5 \mathrm{mg} / \mathrm{kg} /$ infusion in the GABA-CB1 and Glu-CB1 mice, respectively.

After seven sessions of cocaine self-administration (three at FR1 and four at FR2), mice ( $n=7$ Glu-CB1-KO and $n=15$ Glu-CB1-WT, $n=10$ GABA-CB1-KO and $n=12$ GABA-CB1WT) were tested for a dose-response curve at FR2. Six cocaine doses were successively tested in Glu-CB1 $(0.5,0.25$, $0.125,1,0.0625$ and $0.0313 \mathrm{mg} / \mathrm{kg} /$ infusion) and GABA-CB1 mice $(0.25,0.125,0.0625,0.5,1$, and $0.0313 \mathrm{mg} / \mathrm{kg} /$ infusion). Each dose was maintained until the animals reached at least 2 days of stable intake $( \pm 20 \%)$. Self-administration was restabilized at the training dose before mice were tested for a dose-response curve in a PR schedule. Each dose was tested in one PR session after at least 3 days of stable behavior at FR2. Five doses were successively tested in Glu-CB1 $(0.5,1$, $0.12,0.06$, and $0.03 \mathrm{mg} / \mathrm{kg} /$ infusion) and GABA-CB1 mice $(0.25,0.5,0.12,0.06$, and $0.03 \mathrm{mg} / \mathrm{kg} /$ infusion $)$.

\section{Experiment 2: In vivo Microdialysis in the NAc for Extracellular DA in Freely Moving Glu-CB1 and GABA-CB1 Mice}

Naïve-independent groups of Glu-CB1 and GABA-CB1 mice ( $n=4-6$ mice per group) were used to study extracellular DA in the $\mathrm{NAc}$ in response to vehicle $(\mathrm{NaCl} 0.9 \%)$ or cocaine (20 mg/kg i.p.). Cocaine and vehicle were administered at a volume of $10 \mathrm{ml} / \mathrm{kg}$ (i.p.).

\section{Experiment 3: Non Pharmacological Factors Controlling Cocaine Intravenous Self-Administration in Glu- and GABA-CB1 Mice}

Four days after surgery, Glu-CB1 mice ( $n=22$ Glu-CB1-KO and $n=20$ Glu-CB1-WT) and GABA-CB1 mice $(n=15$ GABA-CB1-WT and $n=7$ GABA-CB1-KO) were trained for cocaine self-administration, as in experiment 1 . After acquisition of cocaine self-administration, Glu-CB1 mice were tested for shock-induced suppression of cocaine taking (session 11) and shock cue-induced suppression of cocaine seeking (session 12), cue omission (session 15), cue-induced cocaine seeking (session 18 and 25), and reversal of active/ inactive manipulanda (session 21). Alternatively, after acquisition of cocaine self-administration GABA-CB1 mice were tested for cue-induced cocaine seeking (session 17), shockinduced suppression of cocaine taking (session 22), shock cue-induced suppression of cocaine seeking (session 23), and reversal of active/inactive manipulanda (session 26). Possible influence of successive tests was minimized by introducing sufficient basal self-administration sessions and controlling that mice had recovered their pre-test cocaine intake.

\section{Experiment 4: T-Maze Learning and Reversal in Glu-CB1 Mice}

Independent groups of naïve Glu-CB1 mice ( $n=7-9$ per group) were tested in a T-maze with palatable food as a reinforcer, according to the procedure described in the Supplementary Information. Within T-maze sessions, GluCB1-WT and Glu-CB1-KO were tested in alternation.

\section{Experiment 5: Ex vivo Electrophysiology for Synaptic Plasticity Markers in the Nucleus Accumbens shell (NAcshell) in Glu-CB1 Mice}

Representative mice from experiment 3 ( $n=7$ Glu-CB1-KO and $n=6$ Glu-CB1-WT) were submitted to abstinence for 1 month after the last cocaine self-administration session. The mice contained in the two genotype groups were selected to represent differences in CS-induced reinstatement, reversal and shock cue-induced suppression, and equality in cocaine intake over the entire self-administration procedure. Electrophysiology, as described above, was conducted on 2-3 mice per day. Mice from each genotype were tested alternatively to have a similar impact of additional abstinence on the two genotypes. 


\section{Statistical Analysis}

Analysis of variance with repeated measures was used when appropriate to determine possible group effects and interactions. Experimental group (genotype, two levels: WT and KO) was used as a between subjects factor and time, nose-poke hole (active/inactive), cue (with/without), condition (naïve/abstinent) were used as within-subject factors. Newman-Keuls tests for multiple comparisons post hoc analysis was performed when required. All results are expressed as mean \pm SEM. Differences were considered significant at $p<0.05$. Statistical tests were performed with Statistica 9.0 (StatSoft, Tulsa, OK, USA).

See Supplementary Information for extended details of animals, CB1 immunohistochemistry, drugs, catheters, apparatus, surgery for cocaine self-administration, cocaine intravenous self-administration basal training, T-maze, in vivo microdialysis for DA release in freely moving mice and ex vivo electrophysiology.

\section{RESULTS}

\section{CB1 Expression in Glu-CB1-KO and GABA-CB1-KO Mice}

The CB1 protein is found predominantly in axon terminals of neurons. As a consequence, deletion of the $C B 1$ gene in projecting neurons impacts protein expression in the projection areas (Marsicano and Kuner, 2008).

Compared with the WT mice, the full CB1-KO mice lacked any detectable levels of $\mathrm{CB} 1$ protein, as expected (Figure 1). Deletion of either GABA or glutamatergic-specific CB1 gene decreased CB1 immunostaining across all brain areas studied, yet not in the same degree as in the full $\mathrm{KO}$ genotype. Importantly, when compared with the WT, the degree of loss of CB1 immunostaining in the GABA-CB1-KO was greater than the observed in the Glu-CB1-KO, in agreement with previous observations (Marsicano and Kuner, 2008) confirming that, in general, CB1 is strongly expressed in GABAergic neurons and weakly expressed in glutamatergic neurons.

WT mice showed a strong CB1 immunoreactivity in the cortex, striatum, nucleus accumbens (Figure 1a), and substantia nigra reticulata (Figure 1i). The ventral tegmental area (VTA; Figure 1i), raphe nuclei and locus coeruleus (Figure 1q) showed moderate CB1 immunostaining. Distinct CB1 expression levels were observed among different hippocampal layers (Marsicano and Kuner, 2008) (Figure 1e). The CB1 immunoreactive pattern was uniformly distributed throughout the entire hypothalamic ventromedial nucleus (Vmh; Figure $1 \mathrm{~m}$ ).

Similar to the other structures, a large decrease of CB1 immunoreactivity was observed in the hippocampus of GABA-CB1-KO mice when compared with the WT. However, strong CB1 immunoreactivity was conserved in the inner $1 / 3$ of the hippocampal dentate molecular layer (Figure 1g), corresponding to an important CB1 expression in the glutamatergic mossy cells terminals (Marsicano and Kuner, 2008). Also, dorsomedial and ventral striatum significantly expressed CB1 in glutamatergic neurons. Indeed an important expression was conserved in GABA-CB1-KO, which was strongly reduced in Glu-CB1-KO.
As Compared with their Respective WT, GABA-CB1-KO, but not Glu-CB1-KO, Showed Increased Primary Reinforcing Effects of Cocaine

After acquisition of cocaine intravenous self-administration (see Supplementary Information for detailed results), FR2 and PR dose-response curves were performed to characterize the primary reinforcing properties of cocaine and their strength, respectively.

In Glu-CB1 mice. Independently of the dose, Glu-CB1-KO and their wild-type control littermates (Glu-CB1-WT) did not differ in cocaine self-administration under FR (genotype $\times$ dose interaction, $F_{(5,100)}=0.15$, NS; Figure $\left.2 \mathrm{a}\right)$ and PR conditions (genotype effect, $F_{(1,20)}=0.009$, NS; Figure 2b, Supplementary Figure S1a), suggesting that 'glutamatergic CB1' are not necessary for producing the primary reinforcing effects of cocaine.

In GABA-CB1 mice. GABA-CB1-KO mice displayed a higher sensitivity to the primary reinforcing effects of cocaine compared with WT littermates under FR schedules (genotype $\times$ dose interaction, $F_{(5,100)}=5.91, p<0.001$ ) as revealed by a leftward shift in the dose-response curve (Figure 2c). Accordingly, despite the increase in workload following each infusion, GABA-CB1-KO mice maintained a higher number of self-infusions over a wide range of doses under PR conditions (genotype effect, $F_{(1,20)}=7.15, p<0.05$; Figure 2d, Supplementary Figure S1b).

It is noteworthy that Glu-CB1-WT and GABA-CB1-WT showed differences in the dose-response functions for cocaine self-administration. Differential drug history, notably the training dose, can influence levels of responding for cocaine and is probably responsible for the observed differences. This highlights the importance of comparing each mutant mouse line with its corresponding WT littermate. Nevertheless, when trained at the same dose $(0.5 \mathrm{mg} / \mathrm{kg} /$ infusion, in a preliminary experiment), GABACB1-WT and Glu-CB1-WT showed a similar mean number of infusions over the last 2 days of acquisition, ie $20 \pm 3.3$ and $21.4 \pm 4.8$, respectively (data not shown), supporting the view that differences between the two WT were not pre-existing, but induced by different drug histories.

\section{As Compared with their Respective WT, GABA-CB1-KO, but not Glu-CB1-KO, Showed Increased Cocaine- Induced DA Release in the NAc}

The reinforcing effects of cocaine rely on drug-induced extracellular DA in the NAc (Di Chiara et al, 2004). Given that the reinforcing effects of cocaine were altered in GABA-CB1-KO, but not in Glu-CB1-KO, we used in vivo microdialysis in cocaine naive, freely moving mice, to evaluate the contribution of cocaine-induced DA release in the NAc to these phenotypes.

In Glu-CB1 mice. Extracellular DA in response to an acute cocaine injection $(20 \mathrm{mg} / \mathrm{kg}$ i.p.) was not altered in Glu-CB1-KO (time $\times$ treatment $\times$ genotype, $F_{(22,209)}=0.52$, NS; Figure 2e). 
a

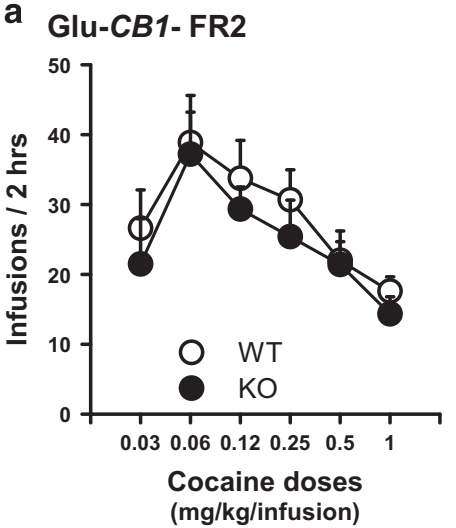

C

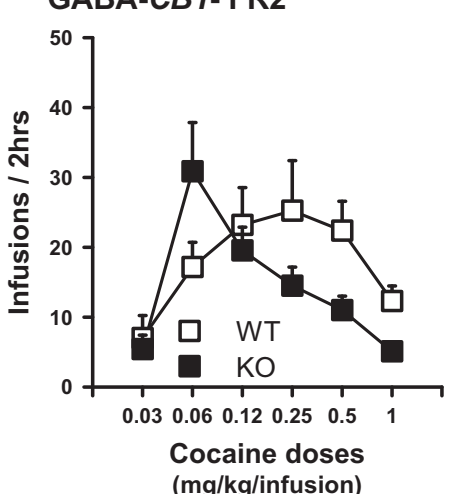

b Glu-CB1-PR

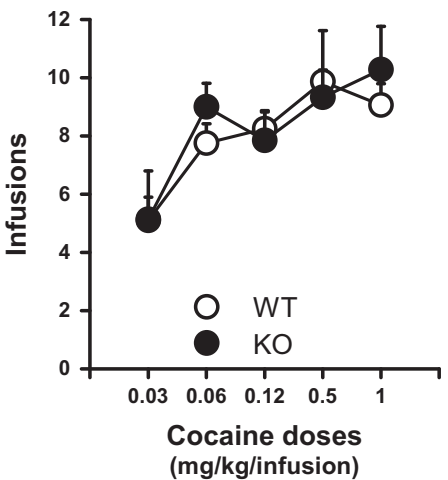

d GABA-CB1 - PR

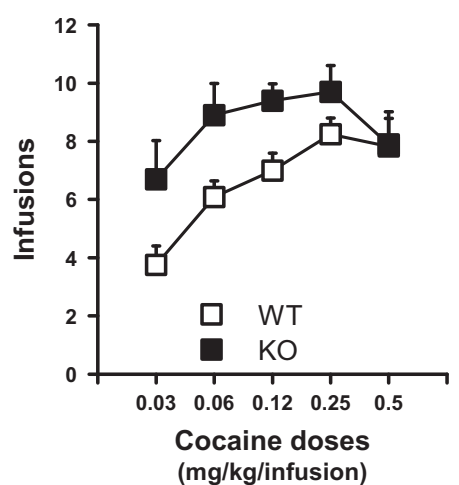

e

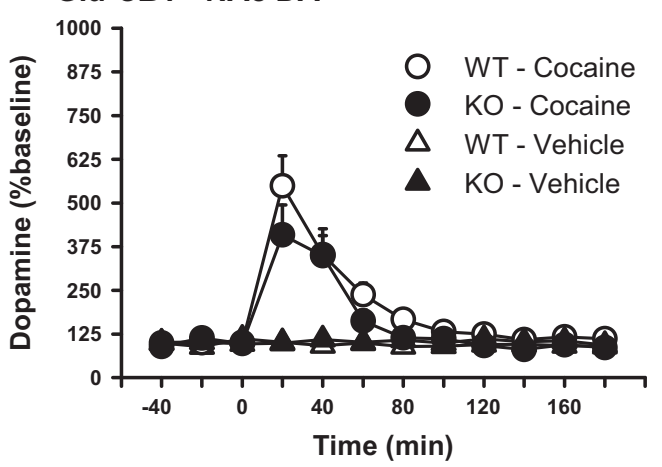

$f$ GABA-CB1 - NAC DA

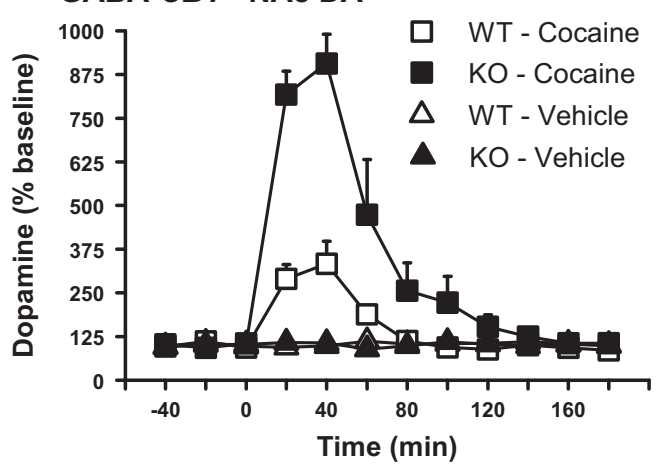

Figure 2 Deletion of $\mathrm{CBI}$ on GABAergic, but not on cortical glutamatergic neurons, increases the primary reinforcing effects of cocaine and cocaineinduced extracellular DA in the NAc. (a) Cocaine self-infusions as a function of dose for intravenous self-administration at fixed ratio 2 schedule (FR2) in Glu$C B I-K O$ mice $(n=7)$ and Glu-CBI-WT $(n=\mid 5)$. (b) Cocaine self-infusions as a function of dose for intravenous self-administration in a progressive ratio schedule (PR) in Glu-CBI-KO $(n=7)$ and Glu-CBI-WT $(n=15)$. (c) Same as (a) in GABA-CBI-KO $(n=\mid 0)$ and GABA-CBI-WT ( $n=\mid 2)$. (d) Same as (b) in GABA-CBI-KO $(n=10)$ and GABA-CBI-WT $(n=12)$. (e) Extracellular DA concentration measured in the NAc by microdialysis in response to vehicle (Veh) and to cocaine $20 \mathrm{mg} / \mathrm{kg}(\mathrm{Coc})$ in freely moving Glu-CBI-KO $(n=4-6$ per condition) and Glu-CBI-WT ( $n=4-6$ per condition). ( $f$ ) Same as (e) in GABA$C B I-K O$ and GABA-CBI-WT. Data are expressed as mean \pm SEM.

In GABA-CB1 mice. In agreement with their increased sensitivity to the reinforcing effects of cocaine, extracellular DA in GABA-CB1-KO was three times larger than GABACB1-WT (time $\times$ treatment $\times$ genotype, $\quad F_{(11,165)}=6.36$, $p<0.001$; Figure 2f).

As Compared with their Respective WT, Glu-CB1-KO, but not GABA-CB1-KO, Showed Facilitated Modulation of Cocaine Seeking by Learning-Related Factors

Associative learning determines key psychological processes involved in controlling cocaine use (Hogarth et al, 2013; Voon et al, 2014), such as incentive motivational responses to cocaine cues. It also influences behavioral inflexibility that consequently can promote compulsive-like behaviors. Therefore, we investigated crucial dimensions of cocaine use that engage associative learning processes in Glu-CB1-KO, GABA-CB1-KO, and their wild-type littermates.

Cue-induced cocaine seeking in Glu-CB1 mice. After 18 self-administration sessions, the light cue previously associated with cocaine infusions induced higher drug seeking in Glu-CB1-KO than in Glu-CB1-WT (hole effect, $F_{(1,31)}=70.03, p<0.001$; time effect, $F_{(5,155)}=8.82, p<0.001$; time $\times$ hole $, \quad F_{(5,155)}=15.87, \quad p<0.001 ; \quad$ time $\times$ hole $\times$ genotype, $F_{(5,155)}=4.51, p<0.001$, Figure $\left.3 \mathrm{a}\right)$. When retested after 25 self-administration sessions, Glu-CB1-WT mice reached the same level of cue-induced cocaine seeking as Glu-CB1-KO (hole effect, $F_{(1,31)}=11.01, p<0.01$; time effect, $F_{(5,155)}=5.56, p<0.001$; time $\times$ hole, $F_{(5,155)}=5.65, p<0.001$; genotype effect, $F_{(1,31)}=1.77$, NS; genotype $\times$ time, $F_{(5,155)}=0.58, \mathrm{NS}$; genotype $\times$ hole $\times$ time, $F_{(5,155)}=1.41, \mathrm{NS}$; Supplementary Figure S1c). These data support that Glu-CB1$\mathrm{KO}$ display facilitated cocaine-cue associative learning, without ultimately altering the motivational or reinforcing value of the cue (see Supplementary Information for detailed results).

Cue omission in Glu-CB1 mice. Supporting that CB1 deletion in the glutamatergic neurons did not alter the motivational or reinforcing value of the cocaine cue, the omission of the latter during self-administration produced a similar decrease in cocaine intake in Glu-CB1-KO and Glu-CB1-WT (cue effect, $F_{(1,31)}=48.66, p<0.001$; genotype effect, $F_{(1,31)}=0.03, \mathrm{NS}$; genotype $\times$ cue, $F_{(1,31)}=0.86, \mathrm{NS}$; Supplementary Figure S1d).

Cue-induced cocaine seeking in GABA-CB1 mice. Despite their increased response to the reinforcing effects of cocaine 
a

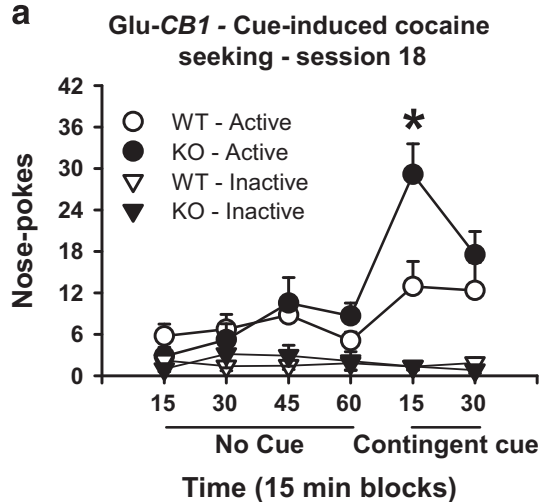

C Glu-CB1 - Holes reversal

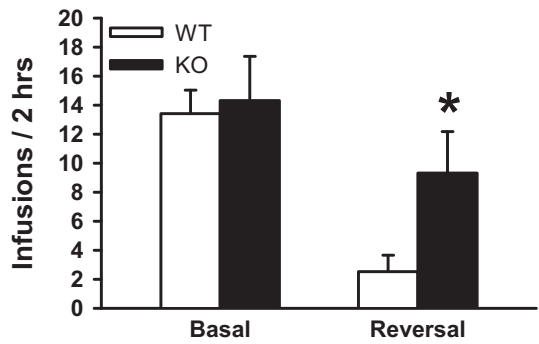

e

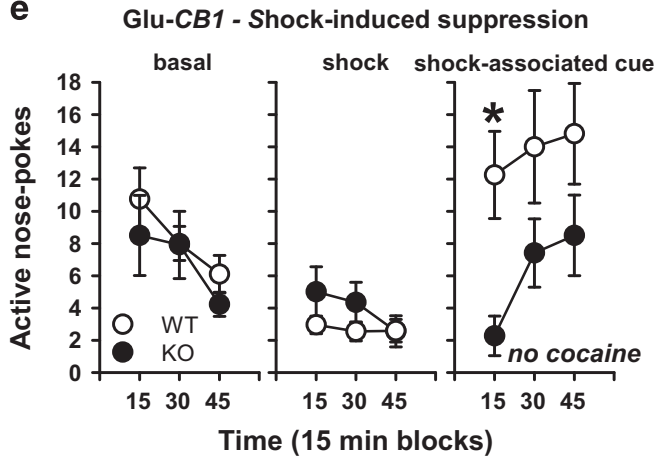

b

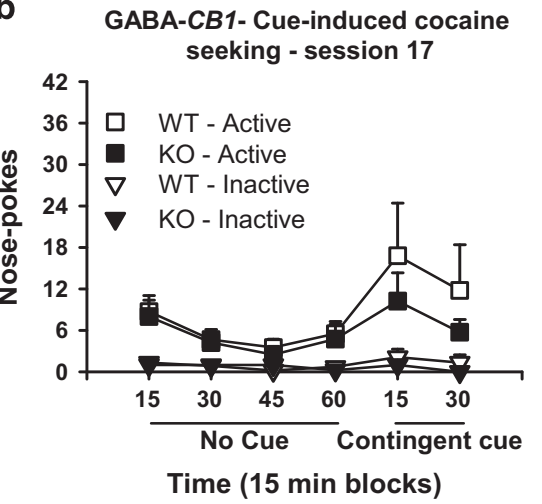

d GABA-CB1- Holes reversal

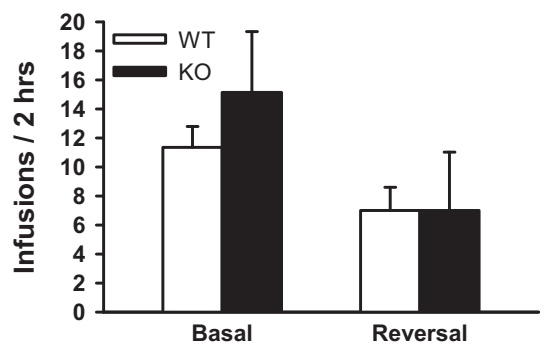

f

GABA-CB1 - Shock-induced suppression

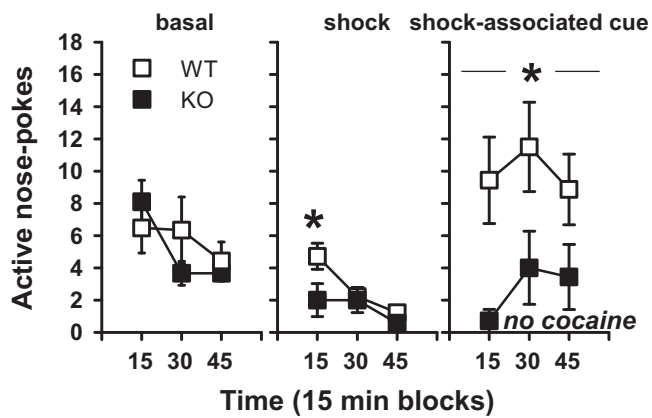

Figure 3 Deletion of $\mathrm{CB}$ I on cortical glutamatergic neurons, but not on GABAergic neurons, facilitates learning-related modulation of cocaine seeking responses. (a) Cue-induced cocaine seeking. Nose pokes in the active and inactive holes during a 60 min period during which nose pokes were not reinforced, followed by a 30 min period during which active nose pokes were reinforced (at FR2) by the cocaine delivery-associated cue light, in Glu-CB /-WT ( $n=\mid 7$ ) and Glu-CBI-KO $(n=\mid 6)$, on self-administration session I8. (b) Cue-induced cocaine seeking. Same as (a) in GABA-CBI-WT ( $n=\mid 5)$ and GABA-CBI-KO $(n=7)$, on self-administration session 17. (c) Reversal. Number of infusions during session 21 where active and inactive holes were reversed compared with preceding basal session 20 in Glu-CB I-WT ( $n=17)$ and Glu-CBI-KO $(n=16)$. (d) Reversal. Same as (c) in basal sessions 25 and reversal session 26 in GABACBI-WT $(n=14)$ and GABA-CBI-KO $(n=7)$. (e) Shock. Basal: Time course of reinforced active nose pokes (cocaine+cue light) in the first 45 min of basal self-administration session 10. Shock: Time course of reinforced active nose pokes (cocaine+cue light) in foot-shock punished 45 min self-administration session (session I I). During this session, the floor was a conductive grid. Foot-shocks were delivered at FRI and then at FR2, I s before cocaine delivery. Shock cue: Time course of non-reinforced active nose pokes in a 45 min session with the foot-shock cue (grid floor) present (session I2), in Glu-CBI-WT ( $n=20$ ) and Glu-CBI-KO (n=22). (f) Shock. Same as (e) in sessions 21 (basal), 22 (shock), and 23 (shock-associated cue) in GABA-CBI-WT ( $n=\mid 4)$ and GABA$\mathrm{CB} I-\mathrm{KO}$ (black squares, $n=7$ ). ${ }^{*} p<0.05$ different from WT. Data are expressed as mean \pm SEM.

(Figure 2c and d), cue-induced cocaine seeking was not altered in GABA-CB1-KO (hole effect, $F_{(1,20)}=13.44$, $p<0.05$; time effect, $F_{(5,100)}=4.32, p<0.05$; time $\times$ hole, $F_{(5,100)}=5.28, p<0.05$, genotype effect, $F_{(1,20)}=0.18$, NS; genotype $\times$ time, $F_{(5,100)}=0.22$, NS; genotype $\times$ hole $\times$ time, $F_{(5,100)}=1.14$, NS) (Figure $3 b$ ) (see Supplementary Results for details).

Reversal of self-administration in Glu-CB1 mice. GluCB1-KO showed increased cognitive flexibility. Reversing active and inactive nose-poke holes over one session reduced cocaine intake in Glu-CB1-WT, but not in Glu-CB1-KO $\left(\right.$ reversal $\times$ genotype, $F_{(1,31)}=4.78, p<0.05$; Figure $\left.3 c\right)$.

Reversal of self-administration in GABA-CB1 mice. GABA-CB1-KO mice showed the same decrease in cocaine intake as GABA-CB1-WT mice in the reversal test $\left(\right.$ reversal $\times$ genotype, $F_{(1,19)}=0.75, \mathrm{NS}$; Figure $\left.3 \mathrm{~d}\right)$.

Reversal of a T-maze task reinforced by palatable food in Glu-CB1 mice. Cocaine specificity of facilitated reversal 
learning in Glu-CB1-KO mutants was tested in a T-maze task using palatable food as reinforcement. Reversal learning of this food-reinforced task was also facilitated in cocaine-naïve GLU-CB1-KO (Supplementary Figure S1e). Glu-CB1-KO mice reversed behavior faster than Glu-CB1-WT (reversal), with accuracy levels (defined as the percentage of correct choices) reaching $90 \%$ by session three in Glu-CB1-KO, compared with $50 \%$ for Glu-CB1-WT mice (genotype effect, $\mathrm{F}_{(1,14)}=6.78, p<0.05$; time effect, $\mathrm{F}_{(4,56)}=83.23, p<0.001$; time $\times$ genotype interaction, $\mathrm{F}_{(4,56)}=3.44, p<0.05$; see Supplementary Information for detailed results).

Shock- and shock-cue-induced suppression of cocaine seeking. Compulsive-like behaviors are intimately related to behavioral inflexibility, but can also be influenced by heightened reinforcing properties. Therefore, Glu-CB1-KO and GABA-CB1-KO could show, respectively, less and more compulsive-like cocaine intake than WT. Therefore, we evaluated the ability of a shock and a shock-associated cue to suppress cocaine seeking.

In Glu-CB1 mice. Baseline (basal) self-administration (first 45 min of the session), shock-induced effect (45 min session), and shock-associated cue-induced effect ( $45 \mathrm{~min})$ on selfadministration were compared (Figure $3 e$ ).

Basal and shock. As compared with baseline (Figure $3 \mathrm{e}$-left panel), when an electric foot shock was associated with drug taking, Glu-CB1-KO and Glu-CB1-WT mice displayed similar decreases in drug seeking (genotype effect, $F_{(1,40)}=1.27$, NS; Figure 3e-middle panel).

Shock-associated cue. Conversely, and further supporting the facilitated associative learning hypothesis, in the absence of both foot shock and cocaine, Glu-CB1-KO showed a greater suppression of drug seeking in the presence of just the shock-associated cue when tested in the same conditions (genotype effect, $F_{(1,40)}=6.68, p<0.05$; Figure $3 \mathrm{e}$-right panel). See Supplementary Information for details.

In GABA-CB1 mice. Baseline (basal) self-administration (first $45 \mathrm{~min}$ of the session), shock-induced effect ( $45 \mathrm{~min}$ session), and shock-associated cue-induced effect (45 min) on self-administration were compared (Figure $3 \mathrm{f}$ ).

Basal and shock. As compared with baseline (Figure $3 \mathrm{f}$-left panel), when an electric foot shock was associated with drug taking, GABA-CB1-KO showed a greater decrease in drug seeking than GABA-CB1-WT (genotype effect, $F_{(1,19)}=4,80, p<0.05$ ) (Figure $3 \mathrm{f}-$ middle panel).

Shock-associated cue. Consistent with the increased shock-induced suppression of intake, GABA-CB1-KO continued showing lower cocaine seeking than GABA-CB1-WT in the following session (genotype effect, $F_{(1,19)}=6.21$, $p<0.05$; Figure $3 \mathrm{f}$-right panel). See Supplementary Information for details.
Increase in AMPAR/NMDAR Ratio in the NAcshell after Cocaine Abstinence Involves CB1 on Cortical Glutamatergic Neurons

AMPAR/NMDAR ratio in the NAcshell in Glu-CB1 mice. We observed an increase in AMPAR/NMDAR ratio in cocaine-experienced mice after 1 month of abstinence as compared with naïve controls (cocaine effect, $F_{(1,49)}=21.44$, $p<0.001$; genotype effect, $F_{(1,49)}=3.70$, NS, genotype $\times$ cocaine, $F_{(1,49)}=2.02$, NS). Interestingly this increase was lower in Glu-CB1-KO than in Glu-CB1-WT (genotype effect, $F_{(1,49)}=21.44, p<0.05$; Figure $4 \mathrm{a}$ ), demonstrating a contribution of Glu-CB1 in the increased AMPAR/NMDAR ratio. Intriguingly, $A M P A R / N M D A R$ ratio was related to the control of cocaine seeking by aversive conditioned cues. Indeed, a correlation was observed between the AMPAR/ NMDAR ratio measured after abstinence and cocaine seeking during shock-associated cues $(r=0.48, p<0.01$; Figure $4 b)$. We observed that the lower the ratio, the greater the influence of shock-associated cues had on suppressing cocaine seeking. No relationship was observed between AMPAR/NMDAR ratio and cue-induced reinstatement or reversal during selfadministration (Supplementary Figure S2a and b).

\section{DISCUSSION}

The present results demonstrate that control of cortical glutamatergic and forebrain GABAergic transmission by CB1 modulates specific complementary components of cocaine self-administration in mice. The differential role of these subpopulations of $\mathrm{CB} 1$ receptors provides a new important advance in the understanding of the neuropsychological role of the ECS, which contrasts with the classical view issued from full CB1 blockade suggesting that these receptors only control glutamate-related dimensions of cocaine responses.

\section{CB1 Expression in Key Brain Areas}

CB1 expression in WT mice was observed in brain areas that were selected for their involvement in cocaine-related behavioral responses (Parsons and Hurd, 2015). In general and as previously shown (Marsicano and Kuner, 2008), the levels of expression of CB1 in glutamatergic neurons were very low as compared with GABAergic neurons, which extensively expressed CB1 protein. However, it is critical to note that the level of expression of CB1 does not translate its functional importance: other factors, such as efficiency of receptor coupling and local synthesis of endocannabinoids, need to be taken into consideration. Although CB1 receptors on cortical glutamatergic cells are less abundant, they can produce more pronounced effects than on GABAergic cells (Steindel et al, 2013).

\section{Deletion of CB1 on GABAergic Neurons Increases the Primary Reinforcing Effects of Cocaine and Cocaine-Induced DA Release in the NAc}

Our data indicate that GABA-CB1 controls cocaine taking by modulating sensitivity to the reinforcing properties of cocaine. Specifically, GABA-CB1-KO mice showed increased sensitivity to operant cocaine self-administration. This was 
a

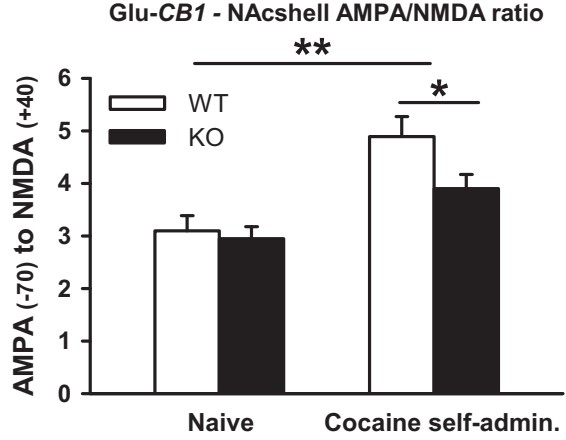

b

AMPA/NMDA vs shock-cue suppression of seeking

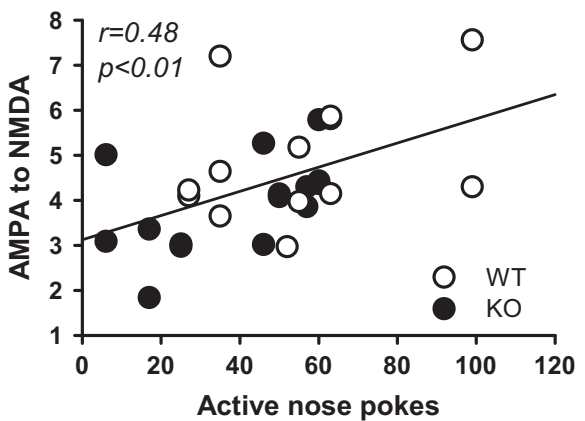

Figure 4 Increase in AMPAR/NMDAR ratio in the NAcshell after cocaine abstinence involves CBI on cortical glutamatergic neurons. (a) AMPAR/NMDAR ratio at synapses on cells of the NAcshell in nairve Glu-CBI-WT $(n=\mid 2)$ and Glu-CBI-KO $(n=\mid 3)$ and in cocaine-experienced Glu-CBI-WT $(n=\mid 3)$ and Glu-CBI-KO $(n=15)$. (b) Correlation between AMPAR/NMDAR ratio and non-reinforced nose pokes in the active hole during shock-induced conditioned suppression seeking. ${ }^{*} p<0.05$ different from $W T$, ${ }^{*} * x<0.0$ l different from Naïve. Data are expressed as mean \pm SEM.

supported by elevated cocaine-induced increase in extracellular DA in the NAc, the primary substrate of cocaine's reinforcing effects (Di Chiara et al, 2004).

Specifically, GABA-CB1-KO showed a leftward and an upward shift in the dose-response curves for cocaine selfadministration for FR and $\mathrm{PR}$, respectively. This phenotype appeared to combine an increased sensitivity to both the aversive and positive effects of the drug. As compared with GABA-CB1-WT, a lower training dose was required for the GABA-CB1-KO mice to acquire cocaine self-administration suggesting an increased sensitivity to the aversive effect of high unit drug doses. Conversely, at low doses, GABA-CB1$\mathrm{KO}$ mice self-administered more than the WT, attesting an increased sensitivity to the positive reinforcing effects of cocaine. In the PR, the workload implies different pharmacokinetics (due to lower frequency of intake) and a lower total intake, which would prevent medium to high unit doses to induce aversive concentrations of cocaine, and thus allowing for increased sensitivity to their rewarding effects.

An increase in sensitivity to both appetitive and aversive stimuli in GABA-CB1-KO is supported by both the present study and data from the literature. Indeed, previous observations revealed increased interest of these conditional mutant mice in novel food or object exploration (Lafenêtre et al, 2009), but also in favoring active coping strategies, such as escape, in fear cued conditioning (Metna-Laurent et al, 2012). In the present study, when we paired cocaine selfadministration with foot shocks, GABA-CB1-KO expressed increased unconditioned and conditioned foot-shockinduced suppression of cocaine seeking. In this conflicting situation, increased sensitivity to the aversive stimulus would supplant increased sensitivity to cocaine and lead to enhanced avoidance of self-administration. Altogether, our data show that GABAergic CB1 are likely involved in damping responses to stimuli, either appetitive or aversive.

Naïve GABA-CB1-KO mice showed increased cocaineinduced DA release in the NAc, suggesting that a DAdependent mechanism could be involved, at least regarding cocaine seeking, which could result from greater disinhibition of DA neurons by GABAergic inputs within the VTA (Lupica and Riegel, 2005; Maldonado et al, 2006).

\section{Deletion of CB1 on Cortical Glutamatergic Neurons Facilitates Learning-Related Modulation of Cocaine Seeking Responses}

Our data indicate that cortical Glu-CB1 controls cocaine taking by limiting associative learning-dependent processes. Environmental cues either associated with cocaine or with aversive stimuli had a stronger impact on drug seeking in these mutant mice probably due to facilitation in conditioned learning. This behavioral profile of Glu-CB1-KO mice was supported by reduced expression of synaptic plasticity markers in the NAcshell.

Our results suggest that $\mathrm{CB} 1$ receptors in cortical glutamatergic neurons are specifically involved in controlling associative learning and therefore in modulating the influence of conditioned stimuli on operant responses. Indeed, Glu-CB1-KO mice did not differ from Glu-CB1-WT regarding cocaine's primary reinforcing effects as revealed by the similar dose-response curves for cocaine self-administration at FR and PR in both genotypes. Conversely, they showed an increased cue-induced cocaine seeking. However, facilitated cue-induced cocaine seeking observed after 18 sessions, was transient, and was not associated with increased motivation in $\mathrm{PR}$ or with perseverative, compulsive like, cocaine seeking in the presence of foot shocks or footshock-associated cues. On the contrary, the decrease in cocaine seeking by foot-shock-associated cues was even higher in Glu-CB1-KO mice. This later finding supports facilitated conditioning and is consistent with their delayed extinction of freezing in fear conditioning experiments (Dubreucq et al, 2012). Altogether these results suggest that increased control of cocaine seeking by cocaine-associated cues in Glu-CB1-KO rely on facilitated associative learning, rather than absolute increased incentive/motivational values of cocaine-related stimuli. Supporting a general facilitation of learning processes, Glu-CB1-KO also showed facilitated reversal of cocaine self-administration and of a T-maze task for a natural reinforcer. Facilitated extinction is an unlikely mechanism for facilitation of reversal in Glu-CB1-KO mice. Consistent with our own observation, CB1 blockade does not alter extinction of appetitive learning (Hernandez and Cheer, 2011). Rather, facilitated inhibitory control of previously 
relevant goal-directed responses could be involved. At low doses, both CB1 agonist HU-210 and antagonist AM251 improve shifting from an egocentric response to a visual-cue guided strategy in a T-maze task (Hill et al, 2006). In the same line, SR141716 improves inhibitory control by decreasing the number of premature, but not perseverative, responses in the 5-CSRTT (Pattij et al, 2007).

Previous studies revealed that CB1 pharmacological blockade attenuates cue- and cocaine-induced reinstatement (Caillé and Parsons, 2006; Cheer et al, 2007; Oleson and Cheer, 2012; De Vries et al, 2001; Xi et al, 2006). Here mice genetically deleted for CB1 in glutamatergic neurons showed an increase of cue-induced reinstatement, and not a decrease. This apparent discrepancy most probably relies on a main difference between pharmacological blockade and genetic deletion in the context of reinstatement. In the first case, absence of $\mathrm{CB} 1$ function occurs acutely during expression of conditioning, while in the second case absence of $\mathrm{CB} 1$ function influences both the conditioning process and its expression. It is possible that the Glu-CB1 receptor regulates conditioning, ie dampens/filters associative learning, during self-administration and promotes expression of a reliable conditioned response during relapse. Critically also, reinstatement relies not only on associative learning and strength of conditioning, but also on the translation of conditioning into a motivational state. Acute pharmacological blockade of CB1 during reinstatement could mainly target the latter. In any case, at this stage, even if it is possible to identify procedural differences that can explain this discrepancy between the effects of $\mathrm{CB} 1$ antagonists and the effects of Glu$C B 1-\mathrm{KO}$ on reinstatement (ie blockade only during reinstatement $v s$ blockade at all stages), it is difficult to speculate on the mechanisms underlying this difference.

Altogether, cortical glutamatergic $\mathrm{CB} 1$ appears to be involved in moderating associative learning by possibly altering the control of conditioned factors on operant responses and compromising behavioral flexibility. Interestingly, negative symptoms of schizophrenia have been related to both increased NAc CB1 receptor binding and altered associative learning that was impeded by the inability to ignore irrelevant stimuli (Ceccarini et al, 2013; Hall et al, 2009).

\section{Increase in AMPAR/NMDAR Ratio in the NAcshell after Cocaine Abstinence Involves CB1 on Cortical Glutamatergic Neurons}

The full exploration of the neurobiological mechanisms underlying the Glu-CB1-KO phenotype in drug- and nondrug reinforced behaviors was beyond the scope of our study. Nonetheless, our results provide important insights to understand these mechanisms.

The NAc, notably its shell part, is considered as a key structure in cue-associated reward behavior (Corbit et al, 2001). Consistently, the NAcshell is critical for cue-induced seeking for both cocaine and natural reinforcers (Guercio et al, 2015; Kalivas and Volkow, 2011). Notably, it has been suggested that the NAcshell is a hub between the circuits that promote, and those that inhibit, cue-induced cocaine seeking (LaLumiere et al, 2012). Changes in the strength of glutamatergic synapses within the NAcshell are proposed to play a determinant role in controlling cue-induced seeking behavior (Loweth et al, 2013; Guercio et al, 2015; Kalivas and Volkow, 2011; Ortinski et al, 2012; Pascoli et al, 2014; Ma et al, 2014). Furthermore, in agreement with previous studies (Kalivas and Volkow, 2011; Ortinski et al, 2012; Pascoli et al, 2014), we observed an increase in AMPAR/ NMDAR ratio in cocaine-experienced mice as compared with naïve controls, which is seen as one of the key indicators of LTP induction and increased synaptic strength (Lüscher and Malenka, 2011).

CB1 receptors located in glutamatergic neurons are key regulators of glutamate release and they modulate the functionality and plasticity of many synapses within the corticostriatal pathway (Loweth et al, 2013; Chiarlone et al, 2014). We hypothesized that they could play a role in this alteration in synaptic plasticity. We reveal that CB1 receptors in glutamatergic neurons are indeed involved in the long lasting increase in the AMPAR/NMDAR ratio produced by cocaine self-administration and withdrawal in the NAcshell. Indeed, AMPAR/NMDAR ratio was increased in all cocaine abstinent mice, but in a lower extent in Glu-CB1-KO as compared with Glu-CB1-WT. This difference was not a pre-existing trait since a similar ratio was found in naïve Glu-CB1-KO and Glu-CB1-WT mice.

The NAcshell is seen as a key structure, not only for guiding appetitive, but also aversive, conditioned behaviors (Corbit et al, 2001). Interestingly, we provide a correlative link between AMPAR/NMDAR ratio after abstinence and cocaine seeking in the presence of foot-shock-associated cues. These two variables are not directly linked, because AMPAR/NMDAR ratio in the NAcshell appears to evolve oppositely from short $(24 \mathrm{~h})$ to long abstinence periods (Ortinski et al, 2012). Rather, the two variables could be independent but controlled by a common mechanism that influences behavioral and neurobiological measures on distinct time-scales.

In future studies, rescuing $\mathrm{CB} 1$ expression in the Glu-CB1$\mathrm{KO}$ and GABA-CB1-KO mice will allow defining the precise neuroanatomical sites involved in the observed effects, establishing direct causal relationships and challenging a possible bias. Indeed if rescue experiments allowed demonstrating that alterations in fear coping strategies in Glu-CB1$\mathrm{KO}$ and GABA-CB1-KO mice are mediated by direct interference of the CB1 receptors (Metna-Laurent et al, 2012), it cannot be discarded that part of the observed effects in cocaine self-administration relies on developmental and/or compensatory changes due to persistent absence of CB1.

\section{CONCLUSIONS}

In conclusion, $\mathrm{CB} 1$ localization critically determines the pharmacological effects of cocaine. Notably, CB1 in forebrain GABAergic neurons modulates sensitivity to cocaine, while $\mathrm{CB} 1$ in cortical glutamatergic neurons modulates associative learning processes. Our results suggest that global targeting of $\mathrm{CB} 1$ obscures the multiple roles of $\mathrm{CB} 1$ in controlling cocaine taking and in defining vulnerabilities to cocaine addiction. We reveal that altered balance of Glu-CB1 and GABA-CB1 activity could participate in the vulnerability to cocaine abuse and addiction. We question the suitability of indiscriminately targeting all $\mathrm{CB} 1$ as a 
therapeutic strategy for cocaine addiction, as simultaneous blockade of Glu- and GABA-CB1 could elicit antagonistic effects.

CB1 modulates numerous neurobehavioral processes and is therefore explored as a target for the treatment of several mental and neurological diseases. Our results provide new insights for a clearer understanding of CB1 neuropathophysiology.

\section{FUNDING AND DISCLOSURE}

The authors declare no conflict of interest.

\section{ACKNOWLEDGMENTS}

We thank Delphine Gonzales and the Genotyping Platform of the NeuroCentre Magendie for mouse genotyping. We thank Cédric Dupuy for providing excellent care to animals. We thank Dr R Rozeske and Vernon Garcia Rivas for precious help with editing. This work was supported by INSERM, the University of Bordeaux and the Aquitaine Region (to VDG, PVP, GM, UM), by the Fondation pour la Recherche Medicale (DRM20101220445), the Human Frontiers Science Program, and the Agence Nationale de la Recherche (ANR Blanc ANR13-BSV4-0006-02) (to GM), the DG Research of the European Commission FP7 [\#HEALTH-F2 2013-602891 (to RM), HEALTH-60319 and ERC-2010-StG-260515 (to GM)], the Spanish 'RETICS-Instituto de Salud Carlos III' (\#RD12/0028/ 0023), the Spanish 'Ministerio de Ciencia e Innovación' (\#SAF2011-29864, no. SAF2011-29864, \#SAF2013-40592-R, no. SAF2013-40592-R) and the Catalan Government 'AGAUR-Generalitat de Catalunya' (\#2009SGR00731 and \#2014-SGR-1547) (to RM), The Basque Government grant BCG IT764-13, Ministerio de Economía y Competitividad (MINECO) grant BFU2012-33334, University of the Basque Country UPV/EHU UFI11/41 and Red de Trastornos Adictivos - Instituto de Salud Carlos III grant RD12/0028/ 0004 (to PG). The FEDER funds support is also acknowledged. EM-G was supported by a 'Sara Borrell' post-doctoral fellowship from the Spanish 'Instituto de Salud Carlos III'. FK was supported by an Aquitaine Region post-doctoral grant.

\section{REFERENCES}

Bellocchio L, Lafenêtre P, Cannich A, Cota D, Puente N, Grandes P et al (2010). Bimodal control of stimulated food intake by the endocannabinoid system. Nat Neurosci 13: 281-283.

Berridge KC, Robinson TE, Aldridge JW (2009). Dissecting components of reward: 'liking', 'wanting', and learning. Curr Opin Pharmacol 9: 65-73.

Bowers MS, Chen BT, Bonci A (2010). AMPA receptor synaptic plasticity induced by psychostimulants: the past, present, and therapeutic future. Neuron 67: 11-24.

Briand LA, Kimmey BA, Ortinski PI, Huganir RL, Pierce RC (2014). Disruption of glutamate receptor-interacting protein in nucleus accumbens enhances vulnerability to cocaine relapse. Neuropsychopharmacology 39: 759-769.

Caillé S, Parsons LH (2006). Cannabinoid modulation of opiate reinforcement through the ventral striatopallidal pathway. Neuropsychopharmacology 31: 804-813.

Ceccarini J, De Hert M, Van Winkel R, Peuskens J, Bormans G, Kranaster L et al (2013). Increased ventral striatal CB1 receptor binding is related to negative symptoms in drug-free patients with schizophrenia. Neuroimage 79: 304-312.

Chaperon F, Soubrié P, Puech AJ, Thiébot MH (1998). Involvement of central cannabinoid (CB1) receptors in the establishment of place conditioning in rats. Psychopharmacology 135: 324-332.

Cheer JF, Wassum KM, Sombers LA, Heien MLAV, Ariansen JL, Aragona BJ et al (2007). Phasic dopamine release evoked by abused substances requires cannabinoid receptor activation. J Neurosci 27: 791-795.

Chiarlone A, Bellocchio L, Blázquez C, Resel E, Soria-Gómez E, Cannich A et al (2014). A restricted population of CB1 cannabinoid receptors with neuroprotective activity. Proc Natl Acad Sci USA 111: 8257-8262.

Corbit LH, Muir JL, Balleine BW (2001). The role of the nucleus accumbens in instrumental conditioning: evidence of a functional dissociation between accumbens core and shell. J Neurosci 21: 3251-3260.

Cossu G, Ledent C, Fattore L, Imperato A, Böhme GA, Parmentier $\mathrm{M}$ et al (2001). Cannabinoid CB1 receptor knockout mice fail to self-administer morphine but not other drugs of abuse. Behav Brain Res 118: 61-65.

De Vries TJ, Schoffelmeer ANM (2005). Cannabinoid CB1 receptors control conditioned drug seeking. Trends Pharmacol Sci 26: 420-426.

De Vries TJ, Shaham Y, Homberg JR, Crombag H, Schuurman K, Dieben $J$ et al (2001). A cannabinoid mechanism in relapse to cocaine-seeking. Nat Med 7: 1151-1154.

Di Chiara G, Bassareo V, Fenu S, De Luca MA, Spina L, Cadoni C et al (2004). Dopamine and drug addiction: the nucleus accumbens shell connection. Neuropharmacology 47 Suppl 1: 227-241.

Dubreucq S, Durand A, Matias I, Bénard G, Richard E, Soria-Gomez E et al (2013). Ventral tegmental area cannabinoid type-1 receptors control voluntary exercise performance. Biol Psychiatry 73: 895-903.

Dubreucq S, Matias I, Cardinal P, Häring M, Lutz B, Marsicano G et al (2012). Genetic dissection of the role of cannabinoid type- 1 receptors in the emotional consequences of repeated social stress in mice. Neuropsychopharmacology 37: 1885-1900.

Fiancette J-F, Balado E, Piazza P-V, Deroche-Gamonet V (2010). Mifepristone and spironolactone differently alter cocaine intravenous self-administration and cocaine-induced locomotion in C57BL/6J mice. Addict Biol 15: 81-87.

Franklin K, Paxinos G (2012). The Mouse Brain in Stereotaxic Coordinates. Academic Press: San Diego.

Gerdeman GL, Schechter JB, French ED (2008). Context-specific reversal of cocaine sensitization by the CB1 cannabinoid receptor antagonist rimonabant. Neuropsychopharmacology 33: 2747-2759.

Goldstein RZ, Volkow ND (2011). Dysfunction of the prefrontal cortex in addiction: neuroimaging findings and clinical implications. Nat Rev Neurosci 12: 652-669.

Guercio LA, Schmidt HD, Pierce RC (2015). Deep brain stimulation of the nucleus accumbens shell attenuates cue-induced reinstatement of both cocaine and sucrose seeking in rats. Behav Brain Res 281: 125-130.

Hall J, Romaniuk L, McIntosh AM, Steele JD, Johnstone EC, Lawrie SM (2009). Associative learning and the genetics of schizophrenia. Trends Neurosci 32: 359-365.

Hernandez G, Cheer JF (2011). Extinction learning of rewards in the rat: is there a role for CB1 receptors? Psychopharmacology 217: 189-197.

Hill MN, Froese LM, Morrish AC, Sun JC, Floresco SB (2006). Alterations in behavioral flexibility by cannabinoid CB1 receptor agonists and antagonists. Psychopharmacology 187: 245-259. 
Hogarth L, Balleine BW, Corbit LH, Killcross S (2013). Associative learning mechanisms underpinning the transition from recreational drug use to addiction. Ann N Y Acad Sci 1282: $12-24$.

Houchi H, Babovic D, Pierrefiche O, Ledent C, Daoust M, Naassila M (2005). CB1 receptor knockout mice display reduced ethanol-induced conditioned place preference and increased striatal dopamine D2 receptors. Neuropsychopharmacology 30: 339-349.

Kalivas PW (2009). The glutamate homeostasis hypothesis of addiction. Nat Rev Neurosci 10: 561-572.

Kalivas PW, Volkow ND (2011). New medications for drug addiction hiding in glutamatergic neuroplasticity. Mol Psychiatry 16: 974-986.

Kober H, Mende-Siedlecki P, Kross EF, Weber J, Mischel W, Hart CL et al (2010). Prefrontal-striatal pathway underlies cognitive regulation of craving. Proc Natl Acad Sci USA 107: 14811-14816.

Lafenêtre P, Chaouloff F, Marsicano G (2009). Bidirectional regulation of novelty-induced behavioral inhibition by the endocannabinoid system. Neuropharmacology 57: 715-721.

LaLumiere RT, Smith KC, Kalivas PW (2012). Neural circuit competition in cocaine-seeking: roles of the infralimbic cortex and nucleus accumbens shell. Eur J Neurosci 35: 614-622.

Loweth JA, Tseng KY, Wolf ME (2013). Using metabotropic glutamate receptors to modulate cocaine's synaptic and behavioral effects: mGluR1 finds a niche. Curr Opin Neurobiol 23: 500-506.

Lupica CR, Riegel AC (2005). Endocannabinoid release from midbrain dopamine neurons: a potential substrate for cannabinoid receptor antagonist treatment of addiction. Neuropharmacology 48: 1105-1116.

Lüscher C, Malenka RC (2011). Drug-evoked synaptic plasticity in addiction: from molecular changes to circuit remodeling. Neuron 69: 650-663.

Ma YY, Lee BR, Wang X, Guo C, Liu L, Cui R et al (2014). Bidirectional modulation of incubation of cocaine craving by silent synapse-based remodeling of prefrontal cortex to accumbens projections. Neuron 83: 1453-1467.

Maldonado R, Valverde O, Berrendero F (2006). Involvement of the endocannabinoid system in drug addiction. Trends Neurosci 29: 225-232.

Marsicano G, Goodenough S, Monory K, Hermann H, Eder M, Cannich A et al (2003). CB1 cannabinoid receptors and ondemand defense against excitotoxicity. Science 302: 84-88.

Marsicano G, Kuner R (2008). Anatomical distribution of receptors, ligands and enzymes in the brain and in the spinal cord: circuitries and neurochemistry. In: Kofalvi A (ed). Cannabinoids and the Brain. Springer: New York, NY, pp 161-201.

Marsicano G, Lutz B (1999). Expression of the cannabinoid receptor CB1 in distinct neuronal subpopulations in the adult mouse forebrain. Eur J Neurosci 11: 4213-4225.

Marsicano G, Wotjak CT, Azad SC, Bisogno T, Rammes G, Cascio MG et al (2002). The endogenous cannabinoid system controls extinction of aversive memories. Nature 418: 530-534.

Martin M, Ledent C, Parmentier M, Maldonado R, Valverde O (2000). Cocaine, but not morphine, induces conditioned place preference and sensitization to locomotor responses in CB1 knockout mice. Eur J Neurosci 12: 4038-4046.

Melis M, Pistis M (2012). Hub and switches: endocannabinoid signalling in midbrain dopamine neurons. Philos Trans $R$ Soc Lond B Biol Sci 367: 3276-3285.

Metna-Laurent M, Soria-Gómez E, Verrier D, Conforzi M, Jégo P, Lafenêtre P et al (2012). Bimodal control of fear-coping strategies by $\mathrm{CB}_{1}$ cannabinoid receptors. J Neurosci 32: 7109-7118.

Mihindou C, Guillem K, Navailles S, Vouillac C, Ahmed SH (2013). Discriminative inhibitory control of cocaine-seeking involves the prelimbic prefrontal cortex. Biol Psychiatry 73: 271-279.

Monory K, Blaudzun H, Massa F, Kaiser N, Lemberger T, Schütz G et al (2007). Genetic dissection of behavioural and autonomic effects of Delta(9)-tetrahydrocannabinol in mice. PLoS Biol 5: e269.

Monory K, Massa F, Egertová M, Eder M, Blaudzun H, Westenbroek $\mathrm{R}$ et al (2006). The endocannabinoid system controls key epileptogenic circuits in the hippocampus. Neuron 51: 455-466.

Oleson EB, Cheer JF (2012). A brain on cannabinoids: the role of dopamine release in reward seeking. Cold Spring Harb Perspect Med 2: a012229.

Ortinski PI, Vassoler FM, Carlson GC, Pierce RC (2012). Temporally dependent changes in cocaine-induced synaptic plasticity in the nucleus accumbens shell are reversed by D1like dopamine receptor stimulation. Neuropsychopharmacology 37: 1671-1682.

Panin F, Cathala A, Piazza PV, Spampinato U (2012). Coupled intracerebral microdialysis and electrophysiology for the assessment of dopamine neuron function in vivo. J Pharmacol Toxicol Methods 65: 83-92.

Parsons LH, Hurd YL (2015). Endocannabinoid signalling in reward and addiction. Nat Rev Neurosci 16: 579-594.

Pascoli V, Terrier J, Espallergues J, Valjent E, O'Connor EC, Lüscher C (2014). Contrasting forms of cocaine-evoked plasticity control components of relapse. Nature 509: 459-464.

Pattij T, Janssen MCW, Schepers I, González-Cuevas G, de Vries TJ, Schoffelmeer ANM (2007). Effects of the cannabinoid CB1 receptor antagonist rimonabant on distinct measures of impulsive behavior in rats. Psychopharmacology 193: 85-96.

Pierce RC, Wolf ME (2013). Psychostimulant-induced neuroadaptations in nucleus accumbens AMPA receptor transmission. Cold Spring Harb Perspect Med 3: a012021.

Reguero L, Puente N, Elezgarai I, Mendizabal-Zubiaga J, Canduela MJ, Buceta I et al (2011). GABAergic and cortical and subcortical glutamatergic axon terminals contain CB1 cannabinoid receptors in the ventromedial nucleus of the hypothalamus. PLoS One 6: e26167.

Roberts DCS (2005). Preclinical evidence for GABAB agonists as a pharmacotherapy for cocaine addiction. Physiol Behav 86: $18-20$.

Schmidt HD, Pierce RC (2010). Cocaine-induced neuroadaptations in glutamate transmission: potential therapeutic targets for craving and addiction. Ann N Y Acad Sci 1187: 35-75.

Soria G, Mendizábal V, Touriño C, Robledo P, Ledent C, Parmentier $\mathrm{M}$ et al (2005). Lack of CB1 cannabinoid receptor impairs cocaine self-administration. Neuropsychopharmacology 30: $1670-1680$.

Soria-Gómez E, Bellocchio L, Reguero L, Lepousez G, Martin C, Bendahmane $\mathrm{M}$ et al (2014). The endocannabinoid system controls food intake via olfactory processes. Nat Neurosci 17: $407-415$.

Steindel F, Lerner R, Häring M, Ruehle S, Marsicano G, Lutz B et al (2013). Neuron-type specific cannabinoid-mediated G protein signalling in mouse hippocampus. J Neurochem 124: 795-807.

Suto N, Elmer GI, Wang B, You Z-B, Wise RA (2013). Bidirectional modulation of cocaine expectancy by phasic glutamate fluctuations in the nucleus accumbens. J Neurosci 33: 9050-9055.

Tachibana Y, Hikosaka O (2012). The primate ventral pallidum encodes expected reward value and regulates motor action. Neuron 76: 826-837.

van der Veen R, Piazza PV, Deroche-Gamonet V (2007). Geneenvironment interactions in vulnerability to cocaine intravenous 
self-administration: a brief social experience affects intake in DBA/ 2J but not in C57BL/6J mice. Psychopharmacology 193: 179-186. Vlachou S, Markou A (2010). GABAB receptors in reward processes. Adv Pharmacol 58: 315-371.

Volkow ND, Fowler JS, Wang G-J, Telang F, Logan J, Jayne M et al (2010). Cognitive control of drug craving inhibits brain reward regions in cocaine abusers. Neuroimage 49: 2536-2543.

Voon V, Derbyshire K, Rück C, Irvine MA, Worbe Y, Enander J et al (2014). Disorders of compulsivity: a common bias towards learning habits. Mol Psychiatry 20: 345-352.
Wiskerke J, Pattij T, Schoffelmeer ANM, De Vries TJ (2008). The role of $\mathrm{CB} 1$ receptors in psychostimulant addiction. Addict Biol 13: $225-238$.

Wolf ME, Ferrario CR (2010). AMPA receptor plasticity in the nucleus accumbens after repeated exposure to cocaine. Neurosci Biobehav Rev 35: 185-211.

Xi Z-X, Gilbert JG, Peng X-Q, Pak AC, Li X, Gardner EL (2006). Cannabinoid $\mathrm{CB} 1$ receptor antagonist AM251 inhibits cocaineprimed relapse in rats: role of glutamate in the nucleus accumbens. J Neurosci 26: 8531-8536.

Supplementary Information accompanies the paper on the Neuropsychopharmacology website (http://www.nature.com/npp) 